\title{
Lake Level in Relation to Rainfall and Sunspots.
}

By Dr. F. Dixey, Government Geologist, Nyasaland Protectorate.

VARIATIONS IN THE LEVEL OF LAkE Nyasa

THE present investigation was commenced towards the end of 1923 as a result of inquiries made as to recent variations in the level of Lake Nyasa; the information was required in connexion with proposed constructional work at or near the southern end of the lake. At the time the only information readily available was a record at the Marine Transport Department of the rise and fall of the lake level at the Bar, Fort Johnston, since I9I6; the additional data now presented have been collected from many sources, and especial thanks are due to several past and present officers of the Marine Transport Department, as well as to residents and missionaries stationed on the lake.

The results of the investigation indicate that the lake level varies in close sympathy with the sunspot numbers. This relation is apparently due to the dependence of the lake level upon evaporation as well as upon rainfall, and to the fact that evaporation is very largely controlled by solar conditions. The researches of W. Köppen and others have established beyond doubt that there is a close connexion between sunspots and tropical temperature, the latter being $I \cdot I^{\circ} F$. higher at sunspot minima than at sunspot maxima. It is reasonable to conclude that evaporation proceeds at a greater rate during the periods of higher temperature; hence at sunspot minima evaporation will be increased and the level of a lake suitably situated will consequently fall, whereas at sunspot maxima evaporation will be decreased and the level of the lake will rise. In the case of Lake Victoria, for example, this relationship has been found to be so intimate that it yields corre-

lation coefficients of between 0.8 and 0.9 ; recent work has shown, however, that, for this lake at least, rainfall is also an important factor. The variations observed in the levels of Lakes Victoria and Albert and in that of Lake George in New South Wales, and shown to be closely associated with the eleven-year periodicity of sunspot phenomena, have now been found to occur in the case of Lake Nyasa also.

Lake Nyasa, the third largest lake in Africa, is the southernmost of the Rift Valley lakes; it is 10,200 square miles in area and 360 miles in length, and it lies at an altitude of about I645 feet. It is exceptionally deep, so that in places its floor extends down to about 670 feet below sea level. The area of the territory drained by the affluents of the lake is about three times that of the lake itself. The evidence of raised beaches shows that the level of the lake has fallen several hundred feet within late geological times. Until within the last few years the lake was drained by the Upper Shire river, which has now, however, become more or less completely silted up.

The curve depicting the variations in the level of Lake Nyasa is shown in the accompanying diagram
(Fig. I), together with those for Lakes Victoria and Albert and also those representing the rainfall of Uganda and the monthly sunspot numbers. It will be seen that Curve 3 , showing the rainfall variation in Uganda according to figures available at the time, indicates that the level of Lake Victoria is undoubtedly dependent upon the rainfall, although the connexion is apparently small. Later work, however, has shown that the relation existing between the lake level and the rainfall of the whole of the surrounding area is much closer than would be supposed from this curve.

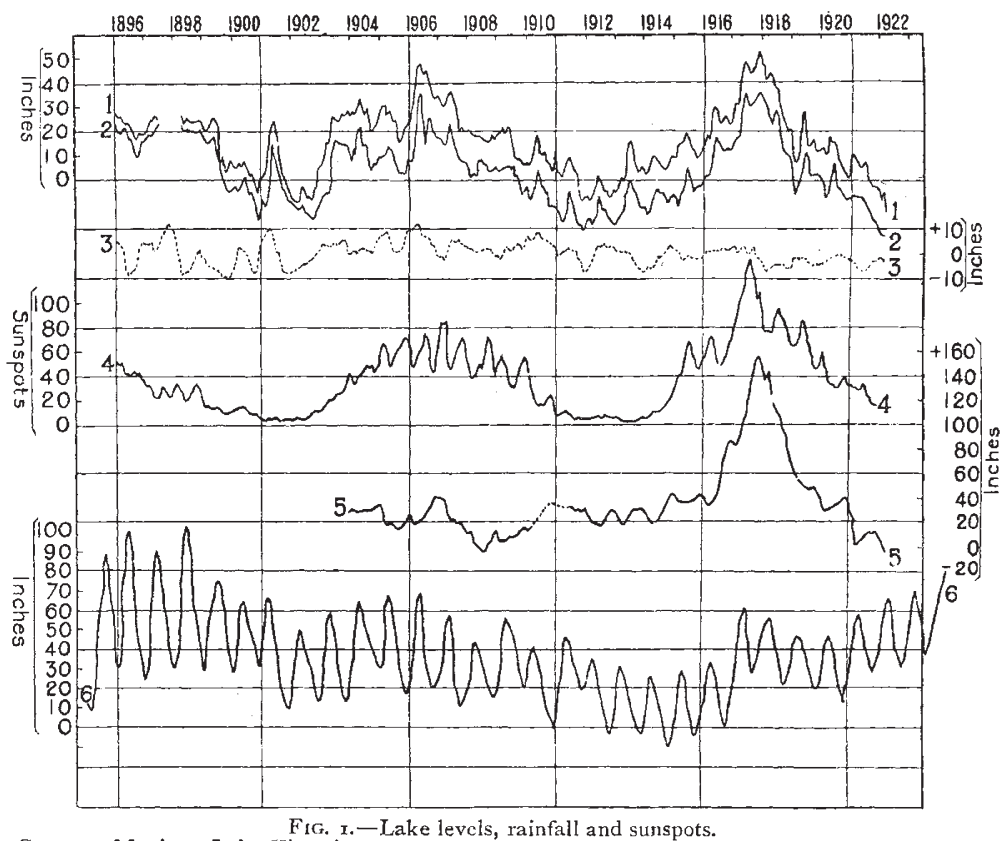

Fig. x.-Lake levels, rainfall and sunspots.

Curve 4. Monthly sunspot numbers.

Curve 5. Lake Albert.

Curve 6. Lake Nyasa: zero on the curve corresponds to $90 \mathrm{ft}$. mark on Lake George at the Bar, Fort Johnston. " "Variations in the
Prooks.

Mr. P. Phillips, Director of the Meteorological Service, Cairo, has recently pointed out that there is actually a very high correlation (0.915) between the rainfall of the "Lake Plateau," which includes parts of Kenya Colony and Tanganyika Territory as well as Uganda, and the change in the level of the lake from year to year.

It is of interest to note that for the period under review the annual variations in the level of Lake Nyasa appear to have decreased, so that while they exceeded six feet in amount between I895 and I899, they have only attained about three feet since 1915; nevertheless, observations made at Cape Maclear for the few years succeeding 1875 show that at that time the variations were again only about three feet. These variations are all much greater than the corresponding changes in the levels of Lakes Victoria and Albert, and they are large also even as compared with the greater variations associated with the sunspot effect.

The curve of the Lake Nyasa levels has been compiled from observations made at different periods and at different stations as follows:

I895-1914, Nkata Bav; I914-I9I6, Monkey Bay;

NO. 287 O, VOL. I I 4 ] 
I916-I924, The Bar, Fort Johnston. Fortunately, the Monkey Bay records overlap those of the other two stations. The first part of the curve, due to Captain E. L. Rhoades, is based upon observations representing for the most part only the approximate maximum and minimum readings for the year, whereas the last part is plotted from readings taken upon the sixth day of each month; nevertheless the relation of the lake levels to sunspot maxima and minima is clearly indicated. In view, however, of the imperfection of the data available, and also of the greater ratio of the annual variation to the " sunspot variation" as compared with Lakes Victoria and Albert, the correspondence between lake level and sunspot numbers is perhaps less satisfactorily indicated than in the case of these two more northerly lakes.

The following relationships as to lake levels and sunspots are evident from a comparison of the curves given in Fig. I. The level of Lake Nyasa stood at a minimum during the sunspot minima of 1902 and I9 3 , and at or near a maximum during the sunspot maxima of I895, I906, and I9I7; similar variations occur in the level of Lake Victoria and also in that of Lake Albert so far as the available records go. Owing to the slightly longer range of the Lake Nyasa records, the sharp rise preceding the maximum of 1895 is more clearly indicated for this lake than for Lake Victoria. Minor maxima in the lake levels occur in I 898, I900, and I9IO-II, two of them at least being clearly related to corresponding minor maxima in sunspot numbers.

An important difference exists between the Lake Nyasa curve for the period I920-23 and the curves of the other lakes for the same period; while the fall following the maximum for I9I7 ceased in the case of the former in 1920 , it continued in the case of the latter for at least another two years. Moreover, early in 1924 the level of Lake Nyasa was higher than it had been at any time since 1898 , and it appears probable that the maximum of 1898 will be reached or even exceeded in the near future. The explanation for these variations may perhaps be connected with exceptionally low level attained by Lake Nyasa about the end of I $9 \mathrm{I} 4$, during the last minimum, when it was lower than it had been for at least twenty years. The accompanying period of depression so much affected the Upper Shire river, which normally formed the outlet of the lake, that it became too feeble to remove not only the silt usually carried by it but also the detritus carried in by its tributaries ; consequently, its bed became more and more silted up until coarse reeds and other forms of vegetation were firmly established upon it. Although the mean annual level of the lake stood more than four feet higher in I923 than in 19I4, and was still rising, the Upper Shire river remained impassable. Moreover, when the river begins to flow again with the first rains of the year, its direction of flow is now reversed, so that from a point about forty miles south of Fort Johnston the water actually flows towards instead of away from the lake. Since the gradient of this part of the valley of the Upper Shire has been given as about six inches per mile, this reversed flow indicates the rising of the river bed through a considerable height. The accumulation of sediment and of vegetation along the course of the river thus acts as a barrier impeding the discharge of water from the lake, and to this barrier may be ascribed the otherwise inexplicable rise of $1920-23$ and afterwards. Further reference to the history of the Upper Shire river will be made in a later paragraph.

The conclusion already drawn from the Lake Nyasa curve that the lake level varies in sympathy with the sunspot numbers receives support from the general statements of early pioneers prior to the commence- ment of the actual measured record in I895. The available data may be summarised as follows:

\begin{tabular}{|l|l|l|}
\hline \multicolumn{1}{|c|}{ Date. } & \multicolumn{1}{|c|}{ Lake Level. } & \multicolumn{1}{c|}{ Sunspots. } \\
\cline { 1 - 3 } I830 & Very low. & \\
I857-63 & Very high. & Maximum about I860. \\
I873 & High. & Maximum about I872. \\
I875-8 & Falling; annual & \\
& variation about & \\
three feet. & High. & Maximum I883-4. \\
I890 & Very low. & Minimum I890. \\
I892-5 & Rising rapidly. & Maximum I895. \\
\hline
\end{tabular}

Marks on the rocks at Monkey Bay and elsewhere indicate that at some early period of unknown date the level stood six feet nine inches higher than in I 897, which otherwise constitutes the highest recorded level. According to native information, this old highlevel period occurred not less than one hundred years ago.

The diurnal variations of level to the extent of about four inches, similar to those recorded from Lake Victoria, occur also on Lake Nyasa, and they may probably be ascribed to the same cause, namely, the influence of the land and lake breezes.

Recording piles have now been established at Kota Kota and Nkata Bay as well as at Fort Johnston, so that there should be available for the future a more detailed and more complete record of the variations of lake level than has been possible in the past.

\section{The Upper Shire River.}

Reference has already been made to the changes that have taken place in the Upper Shire river during recent years. In the early history of the Protectorate the river formed an invaluable highway from the lake down to Matops, a distance of about ninety miles; below Matops almost as far as Chikwawa the river was rendered impassable by the Murchison Cataracts. Navigation for the larger lake steamers, drawing up to 6 feet of water, persisted at least until about I 900 , apart from occasional periods of low water during which it was restricted to the upper reaches of the river. From I905 onwards, owing to a steady fall in the mean annual level of the lake, navigation on the river became more and more difficult, and the lower limit of navigation receded slowly up-stream; about I9Io the river became too shallow even for small craft, and from then until the present day the Upper Shire has been entirely useless as a waterway. As the river fell and the accumulating silt enabled vegetation to become established and this in turn induced a more rapid deposition of sediment, large portions of the river-bed become swampy and ultimately dry. Of late years, as has already been stated, when the river begins to flow with the first heavy rains of the year, it actually carries water for about forty miles into the lake instead of away from it. The accumulations in the river bed have proved so firmly established and so difficult of removal that the steady rise of the lake of the last few years has failed to give the river sufficient power to clear them away; this is the more remarkable when it is considered that not only has the level of 1905 been exceeded, but also that of I 898 , when the river traffic was at its height, is being rapidly approached.

The remarlss made as to the silting up of the Upper Shire apply also to the old Lake Malombe, through which the river passed. The lake is now little better than a large swamp, which is diminishing in area from year to year.

No. 2870 , VOL. I I 4$]$ 
While an essential cause of the present silted-up condition of the Upper Shire was thus in all probability the steady fall of the level of Lake Nyasa from I90 5 to 1914, other factors have probably acted as contributory causes. For example, during the last 60 years or more the Upper Shire valley, in common with other parts of the Protectorate, has been very largely deprived of its natural covering of vegetation; this has of course led to the rapid erosion of soil and even of sub-soil, particularly on the steep hillsides that form the valley walls. The streams flowing swiftly down from the hillsides have carried with them this eroded soil; on reaching the broad flat floor of the Upper Shire Valley, they have been forced to deposit their load in the main river and its larger tributaries. In this way the Upper Shire might well have received more detritus than it could dispose of, even apart from the added difficulty of diminished outflow from the lake. While it is true that the run-off from the hillsides has probably increased in speed and in amount, and should thus have helped to clear the débris, the combination in the main valley of a wide flat floor and steep walls has more probably overcome this factor and led to increased aggregation.

To whatever factor the blocking of the Upper Shire may be due, it is clear that it must bring about a raising of the level of the lake, although from the few figures at present available it appears unlikely that a rise of more than one foot per year at the most would result from this cause alone. In view of the larger variations of lake level due to other causes, however, it is practically certain that earlier or later an unusually high level of the lake would give the Upper Shire river a temporary advantage over the obstructions in its course. Once this advantage were gained the river would in all probability be able for a time to keep its course clear and thus assist in lowering the level of the lake; this process would gradually place the river in danger of becoming silted up again, when the cycle already outlined would begin afresh. It is of interest to note in this connexion that according to native tradition, as I am informed, the upper part of the Upper Shire valley is subject to periodical flooding on a large scale.

One other complication in tracing the history of the Upper Shire river is the possibility of the level of the land along the course of the river, or in the lake basin, having been slowly raised or lowered even within historical times. Certainly, within very late geological time, as proved by the existence of raised beaches, the lake stood several hundred feet above its present level; from the information at present available, however, it would be difficult to say whether the barriers that held the lake up to this great height have been removed by a tilting of the land or by some process of erosion similar to that described in the preceding paragraph. Atternpts are now being made to determine how far available historical records indicate the existence of any such tilting. Certain it is that the strip of country along the line of the lake and the Upper Shire valley is in an unstable condition as compared with the country bordering it; this is evident from its late geological history and the frequent occurrence of earthquakes there even to this day.

\section{Summary AND Conclusions.}

An examination of available records of the rise and fall of Lake Nyasa indicates that the level of this lake, in common with the levels of Lake Victoria and Lake Albert, varies in close sympathy with the number of sunspots; moreover, certain minor variations associated with sunspot phenomena are also common to all three lakes so far back as the records for each can be traced. While the rainfall records of the
Lake Nyasa area are not sufficiently complete to be of value in this connexion, it has recently been shown that, in the case of Lake Victoria at least, a very high correlation exists between lake level and the rainfall of the surrounding plateau; thus the rainfall of the plateau is also closely related to the number of sunspots. Accordingly, in view of the sympathetic variation in the levels of Lake Nyasa and Lake Victoria, and the relation of the level of the latter lake both to sunspot maxima and to rainfall, it is more than possible that the level of Lake Nyasa and the rainfall of its catchment area as a whole may both attain to maximum values in parallel with the elevenyear periodicity of sunspot phenomena. It is of great interest in this connexion to observe that the great drought of $1921-22$ affecting this part of Africa occurred in a period of sunspot minimum, that during this time the levels of Lake Victoria and Lake Albert were both falling at a considerable rate, and that the drought of I9I $I-12$ also occurred in a period of sunspot and lake level minimum. Again, the Lake Nyasa maxima of I896-8 and I9I7 were immediately preceded by periods of exceptionally heavy rainfall. Finally, it has been observed by the older residents of Nyasaland that famines similar to those of I9I2 and 1922 have occurred at intervals of ten or eleven years over a considerable period in the history of the country; thus it is not unreasonable to assume that famines will recur in the future at similar intervals, unless due precautions are taken to avert them.

As regards the level of Lake Nyasa, however, it appears that the condition of the Upper Shire river and its capacity for carrying off excess waters from the lake must act as an additional but irregular factor. The very low level attained by the lake in I9I4, combined with certain other factors, led to such an extensive silting-up of the bed of the river that the succeeding maximum failed to give the river sufficient power to scour out its course. Consequently on passing the maximum the lake level fell but slowly; furthermore, it began to rise again, and rise rapidly, about three years before the anticipated minimum. By the early months of 1924 this rise had brought the level almost up to the high maximum of $1896-8$ when river traffic was at its best, but even so the river remained practically dry and totally unfit for navigation. Hence during the next few years the lake may be expected to rise again at least to the highest level on record; if this rise enables the Upper Shire to remove the obstruction from its bed, the river may begin to assist again in bringing about a lowering of the lake level, and incidentally to become fit for navigation once more. The unexpectedly early and rapid rise of the lake that commenced in 1920 , and even persisted through the drought of I92I-22, may thus be ascribed very largely to the virtual dammingup of the lake outlet by the prolonged accumulation of sediment and vegetation in the bed of the Upper Shire.

While fluctuations of considerable magnitude have occurred in the level of the lake during historic time, there is no evidence to show that any progressive rise or fall has taken place. This is in accord with the findings of a Commission recently appointed in South Africa to inquire into the cause of the disastrous droughts of recent years; it was found that there was no evidence for any progressive increase or decrease in the rainfall of the Union during historic time, and that the desiccation observable in many parts of the country was due, not to diminished rainfall, but to failure of the land to absorb the rain as it fell. The failure was regarded as due largely to the destruction of natural vegetation, to the consequent erosion of soil, and to the hardening of the surface of the land by sun-baking and the trampling of cattle.

$$
\text { No. } 2870 \text {, VOL. I I } 4 \text { ] }
$$

